\title{
Soluble interleukin-2 receptor in patients with glomerular diseases
}

\author{
Huan-Sheng Chen, Ming-Shiou Wu, Tsan-Shin Yen, Wan-Yu Chen
}

\section{Summary}

In this study, we measured the soluble interleukin-2 receptor (sIL-2R) level to evaluate the cellular immune status in 61 patients with different types of glomerular diseases; 40 healthy volunteers were used as control. All patients with glomerular diseases had levels of serum sIL-2R significantly higher than those of the controls $(766 \pm 59$ vs $280 \pm 23 \mathrm{U} / \mathrm{ml}$ $p<0.05)$. Even patients with normal renal function still had higher serum sIL-2R levels than the controls, no matter to which subgroups they belonged (primary glomerulonephritis, lupus nephritis or diabetic nephropathy). Serum sIL-2R levels were similar among the three subgroups. The serum levels of sIL-2R correlated well with age and were significantly higher in older patients, although this was not observed in the control group. Serum sIL-2R levels were significantly higher in patients with active urinary sediment and in patients with impaired renal function and showed a significant negative correlation with creatinine clearance $(r=-0.56 ; p<0.05)$. Although urinary and serum sIL-2R levels were quite well correlated, $(r=0.35 ; p<0.05)$, the urinary levels of sIL-2R did not differ in patients with different disease activity or different renal functions although they had a significant correlation with 24-hour urinary protein $(r=0.39 ; \quad p<0.05)$. Patients with nephrotic syndrome also had higher urinary sIL-2R levels than other patients $(529 \pm 106$ vs $280 \pm 31 \mathrm{U} / \mathrm{ml}$ $p<0.05)$. We conclude that greater $T$-cell activation might contribute to the pathogenesis of different glomerulonephritis entities, and serum levels of sIL-2R can serve as a useful clinical marker of glomerulonephritis activity. Renal function influenced the serum levels of SIL-2R significantly. This factor must be considered when we interpret the data. Urinary sIL-2R levels did not reflect the disease activity as well. This might be due to the secondary influence of the extent of the glomerular protein leak. Further investigation is needed to define the exact excretory pathway of this substance.

Keywords: T-cell activation, glomerulonephritis, interleukin-2, soluble interleukin-2 receptor
Altered humoral immune response to an unknown foreign antigen has long been thought to contribute to the pathogenesis of glomerulonephritis, and recent studies have stressed the important role of the cellular immunity derangement. ${ }^{1}$ In IgA nephropathy (IgAN), for example, abnormal $\mathrm{T}$ helper/T suppressor lymphocyte ratios, ${ }^{1}$ and abnormal hyperfunction of the $\mathrm{T}$-lymphocyte stimulation of $B$ cells have been reported. ${ }^{2}$ In previous studies of membranous glomerulonephritis, the ability of stimulated monocytes to produce interleukin-1 (IL-1) was also shown to be greatly enhanced. ${ }^{3}$

Interleukin-2 (IL-2) and the soluble interleukin-2 receptor (sIL-2R), along with other cytokines, have been widely investigated in many immunological and nephrological disorders because of their key role in the sequence of T cell activation. ${ }^{4,5}$ Most studies of glomerulonephritis and levels of sIL-2R have focused on IgAN or lupus nephritis. ${ }^{6}$ In IgAN, the level of serum sIL-2R was found to correlate with the degree of haematuria, ${ }^{2}$ but in lupus nephritis, the results were conflicting. ${ }^{6,7}$ On the other hand, the status of serum SIL-2R in other types of glomerulonephritis and other glomerulopathies, such as diabetic nephropathy, is not clear.

The purposes of this study were to determine the status of serum sIL-2R in different kinds of glomerular diseases. We intended to delineate the possible role of sIL-2R in the pathogenesis of glomerular diseases and to see whether the measurement of this $T$-cell product can be used as a marker to reflect disease activity. In addition, we measured the urinary excretion of sIL-2R to determine its relationship with serum sIL-2R levels and other disease parameters.

\section{Materials and methods}

\section{PATIENTS AND CONTROLS}

We studied 61 patients with different kinds of glomerular diseases (see box 1). All cases with primary glomerulonephritis or lupus nephritis were confirmed by renal biopsies and all cases with diabetic nephropathy were diagnosed by their typical clinical presentations. There were 31 males and 30 females. Ages ranged from 19 to 84 years (mean age: $41.00 \pm 16.10$ years). Forty-five cases had normal renal function (serum creatinine $<1.5 \mathrm{mg} / \mathrm{dl}$ ) and 16 cases had impaired renal function (creatinine $\geqslant 1.5 \mathrm{mg} / \mathrm{dl}$ ). Twenty-two patients had neph- 


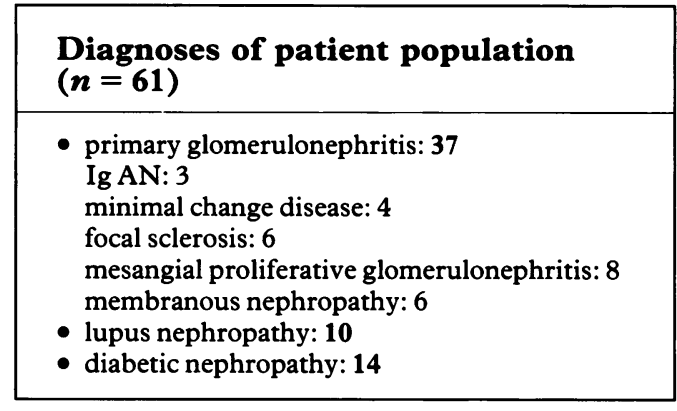

Box 1

rotic syndrome (with proteinuria $\geqslant 3.5 \mathrm{~g} /$ day and clinical presentation of oedema and hypoalbuminemia) and 39 did not. On entering the study, 28 cases had clinical evidence of active kidney inflammation, which was defined as urinary red blood cells $\geqslant 20 /$ high power field or obvious cellular casts in the urine. The other 33 cases with more benign sediments were defined as inactive glomerulonephritis. Forty healthy volunteers (10 males and 30 females) were used as a control group. Ages ranged from 16 to 79 years, (mean age was $36.55 \pm 13.94$ ). All individuals of the control group had normal urine analysis and were infection free.

\section{MEASUREMENT OF URINE AND SERUM LEVELS} OF sIL-2R

sIL-2R levels were measured using a commercially available sandwich enzyme-linked immunosorbent assay (ELISA; T-cell Sciences, Cambridge, MA). Briefly, 96-well microtiter plates were coated with a murine monoclonal IgG antibody raised against the human IL-2 receptor (anti-TAC). After incubation with sample at $37^{\circ} \mathrm{C}$ for four hours, the plates were washed. A second monoclonal antibody, which recognised a second epitope on the sIL-2R, was added. After a second incubation, the plates were washed and the substrate turnover was determined with an ELISA reader at $490 \mathrm{~nm}$. Absorbance readings were converted to Units $/ \mathrm{ml}(\mathrm{U} / \mathrm{ml})$ by comparison to the standard curve. The urine samples were collected in the early morning and the serum samples were collected after fasting with previous normal diet. On entering the study, no patients were receiving immunotherapy, such as steroid or immunosuppressive agents, as all the blood samples were drawn soon after the diagnoses were confirmed and before any treatment began.

BIOCHEMICAL AND SEROLOGICAL PROFILE Blood samples were also used to determine the serum levels of blood urea nitrogen, creatinine, albumin, triglyceride, cholesterol, $\operatorname{IgA}, \operatorname{IgM}$, IgG, C3, C4 and other basic parameters.

\section{DATA ANALYSIS}

All the data were expressed as mean \pm standard error. The correlation between two variables was calculated by the linear regression with the goodness-of-fit tested by the F-test. The nonparametric Mann-Whitney $U$ and Chi-square tests were used for two sample analyses and Kruskal-Wallis tests for three or more samples analyses.

\section{Results}

COMPARISON OF SERUM SIL-2R LEVELS

The average serum level of sIL-2R was $766 \pm 59 \mathrm{U} / \mathrm{ml} \quad(n=61)$ in patients with glomerular diseases and $280 \pm 23 \mathrm{U} / \mathrm{ml}$ $(n=40)$ in the control group (figure 1$)$. The difference was significant $(\mathrm{p}<0.05)$. To rule out the influence of renal dysfunction, we compared only the patients with normal renal function (creatinine $<1.5 \mathrm{mg} / \mathrm{dl}$ ) to the control group (the average creatinine clearances were not significantly different between the former and latter: $79.2 \pm 3.5$ vs $89.5 \pm 4.3 \mathrm{ml} / \mathrm{min}$ ), and found that the serum sIL-2R was still significantly higher in the patient group $(647 \pm 64 \mathrm{U} / \mathrm{ml}, n=45$, vs $280 \pm 23 \mathrm{U} / \mathrm{ml}$, $n=40 ; \mathrm{p}<0.05)$. The significantly higher levels still existed in the subgroups of primary glomerulonephritis $(616 \pm 72 \mathrm{U} / \mathrm{ml}, n=31$ $\mathrm{p}<0.05)$, lupus nephropathy $(965 \pm 214 \mathrm{U} /$ $\mathrm{ml}, n=7 ; \mathrm{p}<0.05)$ or diabetic nephropathy $(506 \pm 96 \mathrm{U} / \mathrm{ml}, n=7 ; \mathrm{p}<0.05)$ when compared with controls, but there were no significant differences of serum sIL-2R levels between the three subgroups.

INFLUENCE OF RENAL FUNCTION, AGE, AND RENAL INFLAMMATORY STATUS ON SERUM sIL-2R

To clarify the influence of renal function on serum levels of $s I L-2 R$, the patients were divided into two groups according to their renal function (creatinine $\geqslant 1.5 \mathrm{mg} / \mathrm{dl} v s<1.5 \mathrm{mg}$ / dl). The serum levels of sIL-2R in the patients with impaired renal function $(1102 \pm 92 \mathrm{U} /$

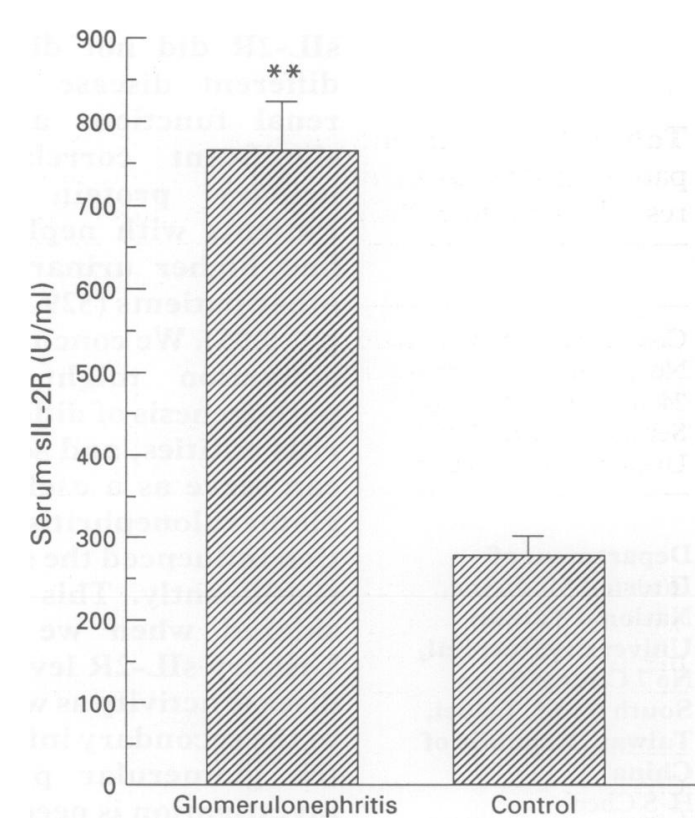

Figure 1 The serum concentrations of sIL-2R in patients with glomerulonephritis $(n=61)$ and in controls $(n=40)$; the former group had a significantly higher level $(\star \star, \mathrm{p}<0.05)$ 
mol, $n=16$ ) were significantly higher than those of the patients with relatively normal renal function $(647 \pm 64 \mathrm{U} / \mathrm{ml}, n=45$; $\mathrm{p}<0.05$, table 1$)$. Using linear regression analysis, we also found that the serum level of sIL-2R showed a good negative correlation with the creatinine clearance $(r=0.56$; $\mathrm{p}<0.05$, figure 2) and a significant correlation with the serum creatinine level $(r=0.35$; $\mathrm{p}<0.05)$. This indicated a strong influence of renal function on serum levels of sIL-2R. We analysed patients with different degrees of proteinuria separately to investigate the influence of this factor (table 2). The serum

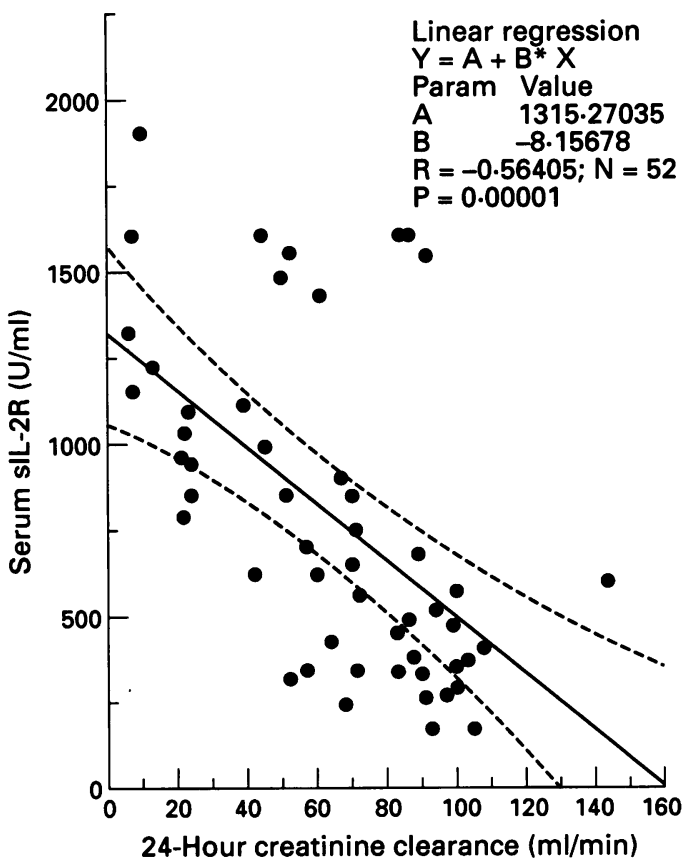

Figure 2 Correlation between the 24-hour creatinine clearance and the serum level of the sIL-2R $(r=-0.56$; $\mathrm{p}<0.05)$

Table 1 Serum and urinary concentrations of sIL-2R between patient groups with different serum creatinine levels (data are expressed as mean $\pm S E M ; C r=$ creatinine; $\mathrm{NS}=$ not significant)

\begin{tabular}{llll}
\hline & $C r \geqslant 1.5 \mathrm{mg} / \mathrm{dl}$ & $C r<1.5 \mathrm{mg} / \mathrm{dl}$ & \\
\hline Creatinine clearance (ml/min) & $20.6 \pm 3.6$ & $79.2 \pm 3.5$ & $\mathrm{p}<0.05$ \\
No patients with active sediment & $6 / 16(37.5 \%)$ & $22 / 45(48.9 \%)$ & $\mathrm{NS}$ \\
24-h urine protein (g) & $2.91 \pm 1.2$ & $5.12 \pm 0.9$ & $\mathrm{NS}$ \\
Serum sIL-2R $(\mathrm{U} / \mathrm{ml})$ & $1102 \pm 92$ & $647 \pm 64$ & $\mathrm{p}<0.05$ \\
Urinary sIL-2R $(\mathrm{U} / \mathrm{ml})$ & $341 \pm 74$ & $371 \pm 54$ & $\mathrm{NS}$ \\
\hline
\end{tabular}

Table 2 Serum and urinary concentrations of sIL-2R in patients with and without nephrotic syndrome (data are expressed as mean \pm SEM; NS = not significant)

\begin{tabular}{llll}
\hline & Nephrotic & Non-nephrotic & \\
\hline Creatinine clearance (ml/min) & $62.0 \pm 5.3$ & $66.2 \pm 6.6$ & $\mathrm{NS}$ \\
Creatinine (mg/dl) & $1.57 \pm 0.4$ & $2.03 \pm 0.4$ & $\mathrm{NS}$ \\
No patients with active sediment & $12 / 22(55 \%)$ & $16 / 39(41 \%)$ & $\mathrm{NS}$ \\
24-h urine protein (g) & $10.5 \pm 1.4$ & $1.21 \pm 0.1$ & $\mathrm{p}<0.05$ \\
Serum sIL-2R $(\mathrm{U} / \mathrm{ml})$ & $855 \pm 109$ & $716 \pm 68$ & $\mathrm{NS}$ \\
Urinary sIL-2R $(\mathrm{U} / \mathrm{ml})$ & $529 \pm 106$ & $280 \pm 31$ & $\mathrm{p}<0.05$ \\
\hline
\end{tabular}

levels of sIL-2R in the patient group with nephrotic syndrome (urine protein $>3.5 \mathrm{~g} /$ day) and the group without nephrotic syndrome were not significantly different $(855 \pm 109$ vs $716 \pm 68 \mathrm{U} / \mathrm{ml})$. In the regression analysis, the serum level of sIL-2R showed no correlation with the values of urinary protein. Among the other clinical parameters, the serum sIL-2R level showed a fair correlation with age $(\mathrm{r}=0.29, n=61, \mathrm{p}<0.05)$. The level in patients over 40 years old was significantly higher than that in younger patients $(884 \pm 89$ vs $652 \pm 73 \mathrm{U} / \mathrm{ml} ; \mathrm{p}<0.05)$, although other parameters such as creatinine level and disease status were similar in both groups. This meant that age itself may be an independent factor influencing serum sIL-2R levels in glomerulonephritis patients; this influence was not found in the control group. The correlations between serum sIL-2R and other data, such as serum IgA, IgM, IgG or C3, C4 were also not significant.

In addition to renal function, we found that the renal inflammatory status influenced the serum level of sIL-2R. In patients with active glomerulonephritis, the serum level of sIL-2R was significantly higher than that of the inactive glomerulonephritis group (852 \pm 92 vs $693 \pm$ $74 \mathrm{U} / \mathrm{ml}, \mathrm{p}<0.05)$. The renal function status was comparable in both groups (table 3 ).

\section{COMPARISON OF URINARY AND SERUM LEVELS} OF sIL-2R

The determination of urinary sIL-2R levels showed quite different results to that of serum levels. Urinary sIL-2R levels were not significantly different between the control and the glomerulonephritis group $(354 \pm 57$ vs $365 \pm 45 \mathrm{U} / \mathrm{ml}$ ) or among the three subgroups. Although urinary and serum levels of sIL-2R showed a good correlation $(\mathrm{r}=0.35 ; \mathrm{p}<0.05$, figure 3 ), there was no definite relationship between renal function and the urinary level of sIL-2R. Urinary levels of sIL-2R also did not differ between patients with active and inactive glomerulonephritis $(391 \pm 91$ vs $346 \pm 43 \mathrm{U} /$ ml, table 3 ) or between patients with impaired or normal renal function (341 \pm 74 vs $371 \pm 54 \mathrm{U} / \mathrm{ml}$, table 1 ), but were significantly higher in patients with urinary protein in the nephrotic range $(529 \pm 106 \mathrm{U} / \mathrm{ml}, n=13)$ than in the patients without $(280 \pm 31 \mathrm{U} / \mathrm{ml}, n=25$, table 2). The influence of proteinuria on urinary sIL-2R levels was further confirmed by the findings of a significant correlation between $24 \mathrm{~h}$ urinary protein and the urinary sIL-2R level $(r=0.39 ; p<0.05)$.

\section{Discussion}

IL-2 is a polypeptide produced by activated $\mathrm{T}$-cells (box 2). After antigen stimulation, it plays a pivotal role in the augmentation of $T$ cell proliferation. ${ }^{8}$ Clinically, however, it is not sensitive enough to differentiate the normal from the disease status by simply measuring the serum level. ${ }^{2}$ The sIL-2R, which is released from the $T$-lymphocyte surface into the plasma upon stimulation, has been shown to be a useful specific marker of T-lymphocyte activation. ${ }^{9}$ 
Table 3 Serum and urinary concentrations of sIL-2R in active and inactive glomerulonephritis patients (data are expressed as mean \pm SEM; GN: glomerulonephritis; NS = not significant)

\begin{tabular}{llll}
\hline & Active GN & Inactive $G N$ & \\
\hline Creatinine clearance (ml/min) & $66.6 \pm 6.4$ & $62.8 \pm 6.4$ & NS \\
Creatinine $(\mathrm{mg} / \mathrm{dl})$ & $1.73 \pm 0.36$ & $1.98 \pm 0.4$ & $\mathrm{NS}$ \\
24-h urine protein $(\mathrm{g})$ & $5.25 \pm 1.2$ & $3.94 \pm 1.0$ & $\mathrm{NS}$ \\
Serum sIL-2R $(\mathrm{U} / \mathrm{ml})$ & $852 \pm 92$ & $693 \pm 74$ & $\mathrm{p}<0.05$ \\
Urinary sIL-2R $(\mathrm{U} / \mathrm{ml})$ & $391 \pm 91$ & $346 \pm 43$ & $\mathrm{NS}$ \\
\hline
\end{tabular}

\section{Properties of IL-2 and its receptor}

- IL-2 is a small $15-\mathrm{kD}$ protein which is secreted after $T$-cell activation

- IL-2 promotes T-cell proliferation through its binding to the IL-2 receptor

- the surface IL-2 receptor consists of two different chains. The smaller chain is released as a $35-40 \mathrm{kD}$ protein and is known as sIL-2R

- sIL-2R is a useful clinical marker of T-cell activation

Box 2

\begin{tabular}{|l|}
\hline Pathophysiology of \\
glomerulonephritis \\
\hline - nonimmune mechanisms may be involved in \\
certain glomerular diseases, such as hereditary \\
nephritis and amyloidosis \\
- essentially, antibody-mediated mechanisms \\
are responsible for most glomerular diseases \\
- evidence of T-cell activation, such as elevation \\
of serum sIL-2R has been revealed in many \\
glomerular diseases
\end{tabular}

Box 3

Serum sIL-2R has been found to be elevated in many clinical conditions, such as collagen disease, infection, organ transplantation, neoplasm and other diseases associated with lymphocyte activation or abnormality. ${ }^{4,5}$

In this study, we clearly show the higher serum level of sIL-2R in patients with different kinds of primary and secondary glomerulonephritis compared to a control group. In patients with primary glomerulonephritis, our result agree with the reports of Yorioka $e t$ al ${ }^{10}$ and Rollino et al. ${ }^{11}$ Although the relationship between cellular immunity derangement and most primary glomerulonephritis was not clearly defined, more and more evidence suggests its contribution to the pathogenesis of different glomerulonephrites. Several reports have shown that, in vitro, the IL-2 level in the supernatant of the stimulated peripheral blood mononuclear cells from patients with IgA nephropathy was significantly higher than that of control subjects, ${ }^{12}$ and the percentage of the IL-2 positive cells (CD25+) also increased when compared with that of control. ${ }^{2}$ Matsumoto et al also reported the enhanced production of IL-1 from stimulated monocytes in different types of glomerulonephritis patients. ${ }^{3}$

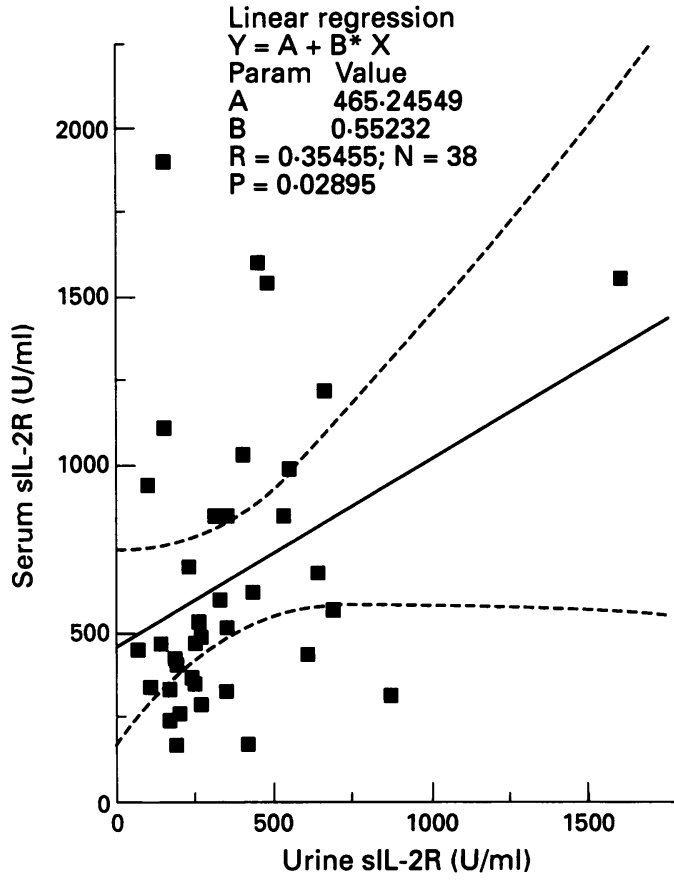

Figure 3 Correlation between the serum and the urine sIL-2R levels $(r=0.35 ; p<0.05)$

In addition, a recent study led by Rollino ${ }^{11}$ shows a good correlation between serum sIL$2 \mathrm{R}$ and $\beta-2$ microglobulin, which is a important component of nucleated cellular membranes. These results, together with ours, strongly encourage further in-depth analysis of lymphocyte stimulation and activation cascades in primary glomerulonephritis patients.

In patients with lupus nephritis, serum sIL$2 \mathrm{R}$ levels were higher than in controls. This result agreed with previous reports ${ }^{5}$ and further confirmed the role of $\mathrm{T}$-cell activation in collagen disease. ${ }^{4}$ Disease activity could be easily monitored using this parameter and it was even more sensitive than the anti-DNA antibody. ${ }^{6}$

From our results, the higher serum sIL-2R levels in patients with diabetic nephropathy had some implications. Although metabolic factors and haemodynamic injury were the two most common theories to explain how hyperglycaemia leads to glomerulosclerosis in diabetic nephropathy patients, $\mathrm{T}$-cell activation had been thought to make an important contribution to the pathogenesis of diabetic nephropathy. Using direct immunofluorescence, Alviggi et $a l^{13}$ found that the levels of activated $T$-cells with HLA-DR expression were significantly higher in patients with insulindependent diabetes mellitus (IDDM) when compared with healthy controls. A study by Bending et $a l^{14}$ using a similar method, also demonstrated that the absolute numbers and percentages of $\mathrm{DR}$-positive $\mathrm{T}$-lymphocytes were significantly higher in diabetic nephropathy patients with proteinuria when compared with those without proteinuria. They emphasized that increased numbers of activated $T$ lymphocytes may be part of the immune-mediated process associated with the development of proteinuria in diabetic neph- 
ropathy. Although the exact mechanism is not fully elucidated, several hypotheses have been proposed to explain why $T$ cells are activated in diabetic nephropathy:

- Modification of the glomerular basement membrane by glycosylation, in conjunction with the HLA class II protein of the mesangium, may confer antigenicity to the membrane and cause the activation of the $\mathrm{T}$ cell. ${ }^{15}$

- The use of insulin: this might be supported by the fact that insulin receptors appear on $T$ cells when they are activated ${ }^{16}$ and in culture, the insulin maintains the $\mathrm{T}$-cell activation status. ${ }^{17}$

In this study, we have confirmed the higher $\mathrm{T}$ cell activation status in patients with diabetic nephropathy by measuring serum sIL-2R. Using this simple and easily applicable tool, further large-sample studies may be conducted to define the influence of different conditions (such as IDDM or NIDDM, the duration of disease, the severity of proteinuria, etc) to this immune derangement.

The renal function and the degree of the proteinuia have been found to influence serum sIL-2R levels in previous studies. ${ }^{10}$ We have therefore analyzed these factors in our patient group. Serum sIL-2R levels correlated well and negatively with the renal function (the level was higher in the group with worse renal function). This implied that the kidney may play an important role in IL-2 clearance and the serum sIL-2R level was obviously influenced by the renal function. This result was consistent with other reports in uraemic and haemodialysis patients. ${ }^{18}$ The degree of proteinuria, on the other hand, did not have a clear relationship with serum sIL-2R levels. This could be explained by the fact that that protein leak itself may involve other immunological mechanisms (such as platelet activation) or structural changes rather than $T$-cell activation if there is no evidence of active glomerular inflammation. ${ }^{19}$ Urinary sIL-2R levels are more dependent on renal protein loss than serum levels. Our results also showed that age itself had a good correlation with serum sIL-2R. Levels were higher in older patients, when other parameters, such as renal function and disease activity, were similar. Although it is well documented that decreased immunological function follows the aging process, these results suggest that $T$-cell derangement might be more prominent in older patients with glomerulonephritis.

In addition to establishing its role in elucidating the possible pathogenesis of glomerulonephritis, we wanted to determine whether serum sIL-2R could be used as a parameter for monitoring disease activity or the renal inflammatory status of glomerulonephritis patients. Previous reports had found that serum sIL-2R, but not IL-2, was higher in IgAN patients presenting with haematuria and the level correlated well with the disease flareup. ${ }^{2,11}$ In our study, the patients in the group with more active urine sediment showed significantly higher serum levels of sIL-2R than those in the group without active sediment. Because the renal function status was

\section{Learning points}

- T-cell activation may contribute to the pathogenesis of glomerular diseases

- serum levels of sIL-2R can serve as a clinical marker of glomerulonephritis activity

- renal function influences serum levels of sIL-2R significantly

- urinary sIL-2R levels do not reflect disease activity well

Box 4

similar in both groups, this significant difference could be explained by the more severe inflammatory process in the glomerulus. Along with the clinical picture and routine examinations such as urinalysis and erythrocyte sedimentation rate, serum sIL-2R may help to monitor disease activity. Recently, a study on lupus nephritis by Tsai et $a l$ showed results conflicting with our own. They found that serum sIL-2R levels did not reflect disease activity well, but that urinary IL-2R did. This may be due to the different definition of the disease activity used and the obscure renal function status of their patients.

An evaluation of cytokines in the urine of glomerulonephritis patients has been recently reported, including sIL-2R and IL- $6 .{ }^{7}$ It was thought that this measurement might give a better picture of the local inflammatory status of the kidney than does serum sIL-2R, which may be influenced by other systemic factors. ${ }^{20}$ This speculation was confirmed by Tsai et $a l^{7}{ }^{7}$ who found a good correlation between urinary sIL-2R and the pathological picture or clinical activity in patient with lupus nephritis. Our study did not show a similar result. Although urinary sIL-2R levels correlate well with serum levels, the former were similar in both active and inactive glomerulonephritis patients. There are several possibilities to explain this. Firstly, urinary sIL-2R might be related to the disease activity, but not be as sensitive as serum sIL-2R levels. Secondly, the different results between studies might be due to the different methology used for determination of urinary sIL-2R. ${ }^{7}$ Thirdly, although urinary sIL-2R may represent the local inflammatory status, its level is influenced by other factors. In this study, we found that the patients with heavy proteinuria had urinary sIL-2R levels higher than those of the patients with mild proteinuira; 24-h urine protein also had good correlation with urinary sIL-2R levels. Thus IL-2R, which has a molecular weight of about 45000 , may possibly leak into the urine as does albumin and influence the true level of locally produced IL-2R. ${ }^{7}$ Lastly we also found that urinary sIL-2R levels were not significantly different from the control group. This implies that the factors that influence urinary sIL-2R levels might be quite complicated. Because the elimination kinetics of this substance in the body have not been clarified, we could not exclude the possibility that decreased renal clearance in the patient group might counteract 
the influence of proteinuria and local active inflammatory processes. A detailed study of the excretory mechanism of this peptide will be necessary to resolve this problem.

1 Feehally J, Beattie T, Brenchley P, Coupes B, Mallick N, Postlethwaite R. Sequential study of the IgA system in relapsing IgA nephropathy. Kidney Int 1986; 30: 924-31.

2 Parera M, Rivera F, Egido J, Campos A. The role of IL-2 and serum-soluble IL-2 receptor cell in idiopathic IgA nephropathy. Clin Immunol Immunopathol 1992; 63: 196-9.

3 Matsumoto K. Interleukin-1 production by monocytes from patients with glomerulonephritis after stimulation in vitro . with soluble immune complexes. Clin Nephrol 1991; 36:

Schmitt WH, Heesen C, Csernok E, Rautmann A, Gross W1. Elevated serum levels of soluble interleukin-2 receptor in patients with Wegener's granulomatosis. Arthritis Rheum 992; 35: 1088-96.

5 Wolf RE, Brelsford WG. Soluble interleukin-2 receptors in systemic lupus erythematosus. Arthritis Rheum 1988; 31: 729-35.

6 Laut J, Senitzer D, Petrucci R, Sablay LB, Barland P, Glicklich D. Soluble interleukin-2 rceptor levels in lupus nephritis. Clin Nephrol 1992; 38: 179-84.

7 Tsai CY, Wu TH, Sun KH, Lin Whu-Mei, Yu Chia-Li. Increased excretion of soluble interleukin 2 receptors and free light chain immunoglobulins in the urine of patients with active lupus nephritis. Ann Rheum Dis 1992; 51: 168-72.

8 Uchiyama $T$, Broder $S$, Waldmann $T$, A monoclonal antibody (anti-Tac) reactive with activated and functionally mature human T cells. I. Production of anti-Tac monocmature human $T$ cells. I. Production of anti-Tac monoclonal antibody and

Rubin LA, Kurman CC, Fritz ME, et al. Soluble interleukin 2 receptors are released from activated human lymphoid cells in vitro. $\mathcal{F}$ Immunol 1985; 135: $3172-7$.

10 Yorioka N, Hirabayashi A, Kanahara K, et al. Serum soluble interleukin-2 receptor in patients with glomerulonephritis. Am $\mathcal{F}$ Nephrol 1990; 10: 181-5.
We would like to thank Ta-Tung Kidney Research Fund for supporting this investigation.

11 Rollino C, Roccatello D, Amprimo MC, et al. Soluble interleukin-2 receptors and $\beta-2$ microglobulin in patients with primary glomerulonephritis. Am $\mathcal{f}$ Nephrol 1993; 13: 244-8.

12 Lai KN, Leung JCK, Lai FM, Tam JS. T-lymphocyte activation in IgA nephropathy: serum-soluble interleukin 2 receptor level, interleukin 2 production, and interleukin 2 receptor expression by cultured lymphocytes. $\mathcal{f}$ Clin Immunol 1989; 9: 485-92.

13 Alviggi L, Johnston C, Hoskins PJ, et al. Pathogenesis of insulin-dependent diabetes: a role for activated $T$ lyminsulin-dependent diabetes: a

14 Bending JJ, Lobo-Yeo A, Vergani D, Viberti G. Proteinuria and activated $\mathrm{T}$-lymphocytes in diabetic nephropathy. Diabetes 1988; 37: 507-11.

15 Fillit HM, Zabriskie JB. Cellular immunity in glomerulonephritis. Am f Pathol 1982; 109: 227-43.

16 Helderman JH, Strom TB. Role of proteinuria and RNA synthesis in the development of insulin binding sites on activated thymus-derived lymphocytes. $\mathcal{F}$ Biol Chem 1979, 254: 7203-7.

17 Kumagai JI, Akiyama $\mathrm{H}$, Iwashita S, Iida H, Yakara I. In vitro regeneration of resting lymphocytes from stimulated lymphocytes and its inhibition by insulin. $f$ Immunol 1981 ; 126: 1249-54.

18 Walz G, Kunzendorf U, Josimovic-Alasevic O, et al. Soluble interleukin 2 receptor and tissue polypeptide antigen serum concentrations in end-stage renal failure. Nephron 1990; 56: concentrations in end-stage renal fallure. Nephron 1990; 56:

19 Mahan JD, Sisson-Ross S, Vernier RL. Glomerular basement membrane anionic charge site changes early in aminonucleoside nephrosis. Am $\mathcal{f}$ Pathol 1986; 125: 393-401

20 Tomino Y, Funabiki K, Ohmuro H, et al. Urinary levels of interleukin-6 and disease activity in patients with IgA nephropathy. Am $\mathcal{J}$ Nephrol 1991; 11: 459-64. 